\title{
Distribution and Overlap of Five Coastal Indo- Pacific Cetacean Species
}

\begin{abstract}
There are many cetaceans that exist in the Indo-Pacific region, however precise distributional locations are difficult to come across. The purpose of this study was to examine reliable literature in order to generate the distributional properties of five cetaceans. Individual spatial locations were combined to reveal where the five species overlapped. The habitat preferences of each species were also gathered in attempt to suggest possible correlations between specific cetacean overlap. Geographical barriers were observed for their distributional effects on the five species. There was a correlation between cetaceans with similar habitats and overlapping distribution. Biogeographical barriers, the Wallace and Lydekker line seemed to play a significant role in isolating certain species. Some cetaceans were permanently separated from other populations due to barriers of the Wallace and Lydekker line. It is possible that new species have diverged as a result of population isolation.
\end{abstract}

Volume 2 Issue 4 - 2015

\author{
Jennifer Alexa Cheznowski \\ Department of Marine Research, Canada
} Correspondence: Jennifer Alexa Cheznowski, Department of
Marine Research, Toronto, Ontario, Canada,

Email jenniferchez@trentu.ca, acheznowski@gmail.com

Received: June 17,2015 | Published: August 27, 2015

\section{Introduction}

Distributional knowledge of some cetacean throughout the Indo-Pacific region are poorly documented. For years, researchers have recorded sightings of dolphin and porpoise species throughout surrounding Indo-Pacific waters, however accuracy of complete distributions are limited. One of the main purposes of developing distributional data ranges is to implement conservational practices. ${ }^{1}$ A mandatory requisite to apply for such practices require an understanding of the spatial attributions. Researchers who document new sightings often publish the records into scientific journals. The difficulty in obtaining accurate cetacean location often results in many hypothetical distributions. The hypothesized distributions are generated through the species known habitat preferences, however theorized locations can result in inaccurate representation of where a species resides. The area in which a species is located is suitable to their unique development. Factors that impact whether a species is restricted to a specific region may have to do with their physical structure. Specialized structures are designed for unique activities. The area in which a species resides is typically due to the fact that the environment provides adequate resources for survival activities. ${ }^{2}$ Suitable niche or habitat must be appropriate to cetacean's abilities. Often, preferred habitat can overlap with another species distribution. An overlap is when one animal will reside within the boundaries of another. $^{3}$

Overlapping can occur when two or more species acquire similar resources within the niche. An overlap can exist where resources are abundant, attracting several different species to overlap in one given area. A common resource is water temperature. Certain coastal species can only survive in warmer water temperatures, and therefore need to remain in a habitat that provides accordingly. Water depth is another factor that effects animal's habitat requirements. Coastal waters provide shallow depths, offering warmer temperatures. Substrates such as coral reefs, sandy bottoms and sea grass play a role in a species habitat preference. Some species prefer less salinity, and therefore will be found in distributions surrounding estuarine waters, a combination of salt and fresh water ${ }^{4}$ Others prefer tropical waters with salinity. Regardless of the habitat factors, certain species may be limited to specific environments due to biogeographical reasons.
Often, unsuitable habitats can prevent a species from entering or crossing over and act as a type of barrier. Such conditions are not suitable for its survival and can lead the animal into great danger. A possible biogeographical barrier within the Indo-Pacific region is the Wallace and Lydekker line situated within Wallacea. ${ }^{5}$

Five coastal cetacean species were observed for their distributional and overlapping patterns within the Indo-Pacific region. These included: the Australian snubfin dolphin (Orcaella heinsohni), the Irrawaddy dolphin (Orcaella brevirostris), the Indo-Pacific finless porpoise (Neophocaena phocaenoides), the Indo-Pacific humpback dolphin (Sousa chinensis) and the Indo Pacific bottlenose dolphin (Tursiops aduncus). Although each of the above species resides with the Indo-Pacific area, they all have a different distributional region. Some of them seem to overlap with others in specific areas. The objectives were to gather information of the five cetacean distribution and habitat preferences by searching through scientific journal articles and other reliable publications. The construction of spatial attributions for each individual species would help to visually identify locations. The next objective was to compute the individual collections into a larger display by combining the confirmed sighting, generating a visual of the overlapping that may exist between the five cetaceans. Upon completion of individual overlapping visual displays, the final objective was to gather reasoning behind certain overlapping and distribution between the cetaceans.

\section{Methods}

The five species were specifically chosen for distributional analysis because their primary locations were all within the Indo-Pacific region. Primary literature search was conducted through scientific journal publications, encyclopedias and trusted websites. Most of the research was collected through journal articles, to ensure the information was accurately obtained. Habitat preferences and cetacean recorded sightings were gathered through primary literature search. The main factors included: substrate, water temperature, water depth, travel distance from shore, and water salinity. The recorded sightings from sources were organized and plotted onto a rough distributional map draft for each species. The rough draft was then administered onto a map building computer software, where each sighting was 
marked in red, highlighting the confirmed cetacean locations only. The distributional areas that did not have confirmed sightings, but were appropriate areas of possible locations according to habitat preference research, were highlighted in orange. The confirmed sightings were labeled on the maps, identifying which source the documented location belonged to. Green highlighted regions were marked to represent the Wallace and Lydekker line within Wallacea. One map was generated for each species, for a total of five confirmed and hypothesized distributional regions.

Confirmed locations were combined to generate a map revealing overlapping regions between the five cetaceans. In order to indicate the number of species overlapping throughout certain regions, specific colours were highlighted to represent the number of cetaceans overlap with a given area. Green indicated that only one species resided in the highlighted area, blue refereed to two species, pink referred to three species, and yellow referred to four species. Overlapping distributions were generated from confirmed sightings only to identify definite cohabitat regions.

\section{Result}

\section{Australian snubfin dolphin (Orcaella heinsohni)}

Distribution: The Australian snubfin is mainly found distributed around the northern portions of Australian waters, surrounding areas of Papua New Guinea and Indonesia (Manokwari). In Australia, the species can be found from Broome to Brisbane. The red markings highlight the confirmed sightings, while the orange highlight the hypothesized (Figure 1). For this species, the Lydekker line seems to play a more significant role than the Wallace. The population does not pass the Lydekker line and the distribution is located along the borders of the line. Each journal article concluded the same distributional regions for the Australian snubfin dolphin (Figure 1).

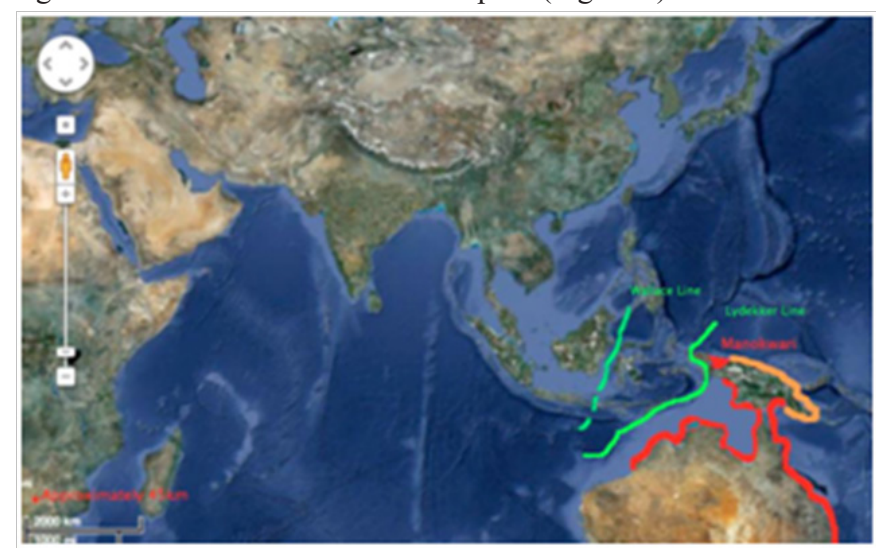

Figure I Hypothesized and confirmed distribution of Australian snubfin dolphin (Orcaella heinsohni).

Hypothesized regions of distribution (orange), primary region of distribution (red), Wallace line (green). Thickness of red line represents approximately $45 \mathrm{~km}$, indicating maximum distance this species is likely to travel away from the coastline. (Each journal article obtained on the distribution of this species confirmed the same locations)

Habitat: The coastal species can be found in tropical, salt and estuarine waters. They prefer a substrate that consists of sea grass or coral reef. Typical depth for the Australian snubfin is approximately $30 \mathrm{~m}$, however comfortable water depth is less than $20 \mathrm{~m}$. This species does not travel farther than $45 \mathrm{~km}$ from the shoreline. They are often found over dredged channels, bringing in warm tropical temperatures (Table 1).

\section{Irrawaddy dolphin (Orcaella brevirostris)}

Distribution: Confirmed sightings of the Irrawaddy dolphin are within the Bay of Bengal, Irrawaddy and Mekong rivers, Indonesia, Kuching Bay Sarawak, Borneo Malaysia, Chilika Lake in India, Ayayarwady River in Myanmar, Songkhla Lake in Thailand and Mahakam River in Indonesia. Three small populations were also found in Visayas, Minadano and Palawan in the Philippines (Figure 2). The Irrawaddy dolphin is distributed above the northern portion of the Wallace line. The Wallace line seems to play a more significant barrier role than the Lydekker line. The distribution lies directly on the border of the Wallace line; however one confirmed sighting is recorded just below the line. The three populations in the Philippines is another distribution of the species that is away from the Wallace line (Figure 2).

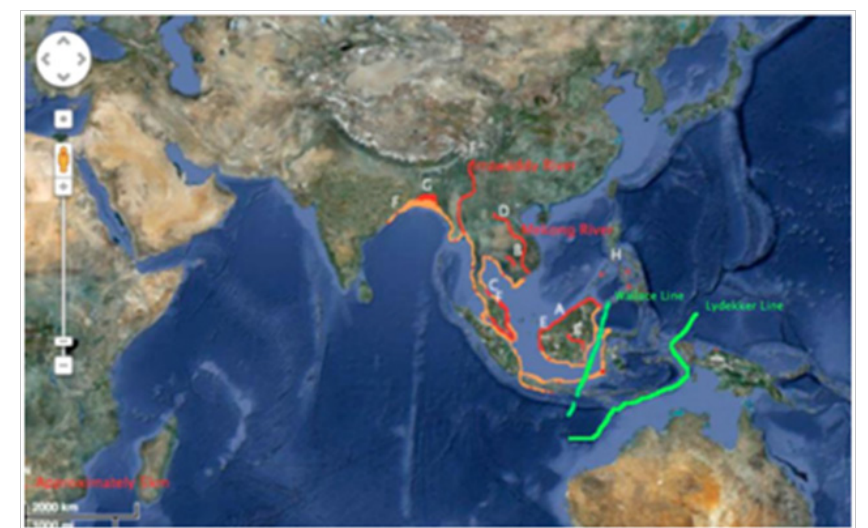

Figure 2 Hypothesized and confirmed distribution of Irrawaddy Dolphin (Orcaella brevirostris).

Hypothesized regions of distribution (orange), primary region of distribution (red), Wallace line (green). Borneo Malaysia (A). ${ }^{16}$ Cambodian Mekong River (B). ${ }^{17}$ Southern Lake, Gulf of Thailand (C). ${ }^{18}$ Mekong River (D). ${ }^{19}$ Kuching Bay, Sarawak (E). ${ }^{20}$ Chilika Lake, India; Ayeyarwady River, Myanmar; Songkhla Lake, Thailand; Mahakam River, Indonesia (F). ${ }^{21}$ Bay of Bengal (G). ${ }^{7}$ Visayas, Mindanao and Palawan, Philippines $(\mathrm{H}){ }^{20}$ Thickness of the red line represents approximately $5 \mathrm{~km}$, indicating maximum distance this species is likely to travel away from the coastline.

Habitat: The Irrawaddy dolphin is likely to be found in low salinity regions such as estuaries and rivers. They prefer muddy, brackish waters that contain mangroves. Typical depth for this species is between $2.5-18 \mathrm{~m}$. Between the five cetaceans, this species remains the closest to shore line, at $5 \mathrm{~km}$ (Table 2).

\section{Indo-pacific finless porpoise (Neophocaena phocaenoides)}

Distribution: The highlighted region in yellow, belong to the distributional area of the narrow-ridged finless porpoise (Neophocaena phocaenoides), a species in the same family as the Indo-Pacific finless porpoise. The narrow-ridged finless porpoise is mainly distributed within the Yellow Sea and the southern portion of Japan. The orange highlights the overlap distribution between the Indo-Pacific finless porpoise and the narrow-ridged finless porpoise. Overlap consists between Lingding Bay, Hong Kong to Ningbo, China. The confirmed distribution of the Indo-Pacific finless porpoise lies within the Persian 
Gulf, across Iran, Pakistan, India, Bangledesh, Myanmar, Thailand, Malaysia, Indonesia (in areas above the Wallace line), Cambodia and Vietnam (Figure 3). The Wallace line seems to play the most significant barrier role for this species. The distribution remains very close to the borders of the Wallace line however, unlike the Irrawaddy dolphin; the Indo-Pacific finless porpoise does not cross the geographical barrier (Figure 3).

Table I The habitat differences between five species ${ }^{6,21,33,40,41}$

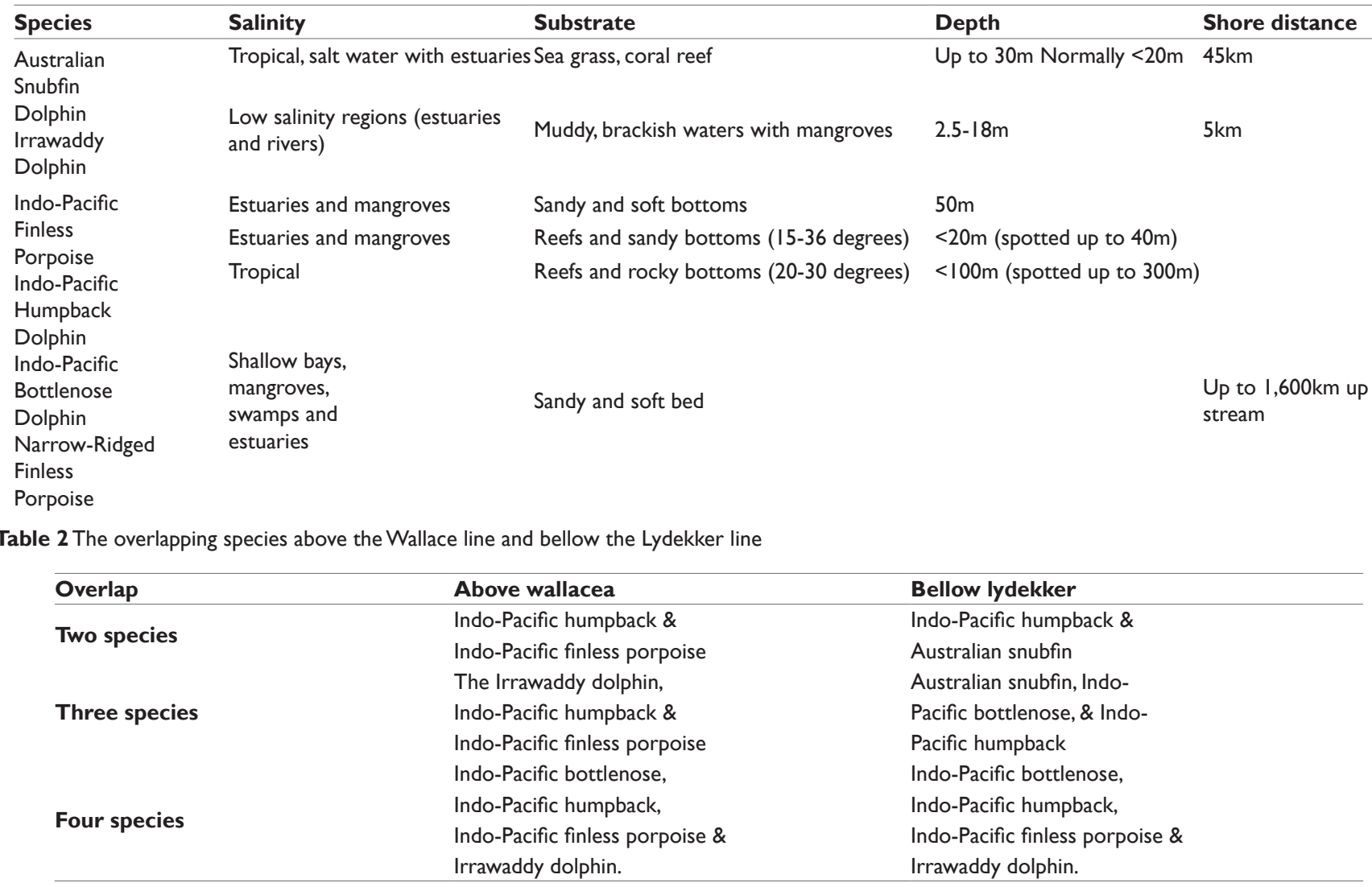

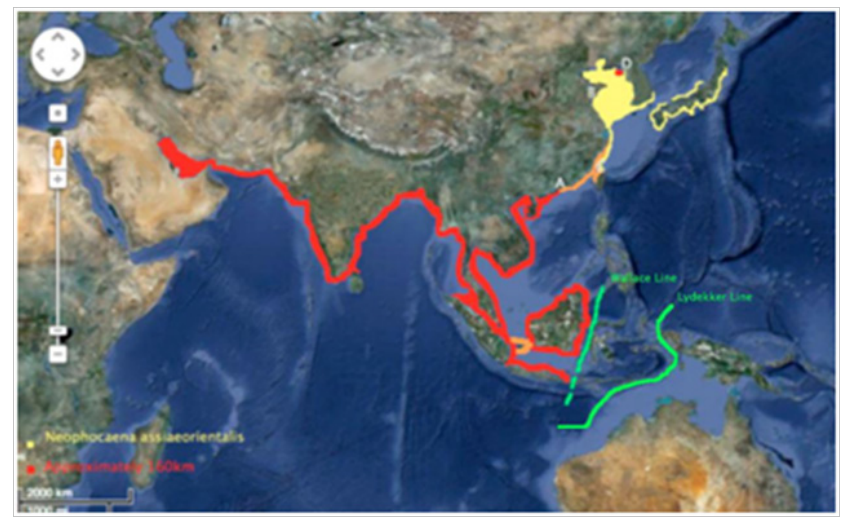

Figure 3 Hypothesized and confirmed distribution of Indo-Pacific Finless Porpoise (Neophocaena phocaenoides).

The distribution of Neophocaena phocaenoides (red), Neophocaenoides asiaeorientalis (yellow), hypothesized overlap of both species (orange), Wallace line (green). Lingding Bay, Hong Kong (A). ${ }^{22}$ Yellow Sea, (B). ${ }^{23}$ Beigan and Nangan, Matsu Islands (C). ${ }^{24}$ Bohai Sea region (D) ${ }^{25}$ Thickness of red line represents approximately $160 \mathrm{~km}$, indicating maximum distance that Neophocaena phocaenoides is likely to travel away from the coastline.
Habitat: The Narrow-Ridged finless porpoise prefers shallow bays, mangroves, swamps and estuaries. Typical substrates include sandy and soft beds. This species has been known to travel $1600 \mathrm{~km}$ up rivers from the Yellow Sea. The Indo-Pacific finless porpoise prefers estuaries and mangroves. Ideal substrates include sandy and soft bottoms. This species is not likely to travel farther than $50 \mathrm{~km}$ from the shoreline (Table 1).

\section{Indo-pacific humpback dolphin (Sousa chinensis)}

Distribution: The Indo-Pacific humpback dolphin is distributed from the coast of Bangladesh, Myanmar, Thailand, Cambodia, Vietnam, western China, northwestern Taiwan, eastern Malaysia and northern Australia (Figure 4). The northern population of this species seems to be influenced by the Wallace line, where the Lydekker line seems to play the most significant barrier effect on the southern population (Figure 4).

Hypothesized regions of distribution (orange), primary region of distribution (red), Wallace line (green). Xiamen (A). ${ }^{26}$ Taiwan (B). ${ }^{27}$ China (C). ${ }^{28}$ Pearl River (D). ${ }^{29}$ Leizhou Bay (E). ${ }^{30}$ Donghai Island, China $(\mathrm{F}) .^{31}$

Habitat: Primary salinity preference includes estuaries and mangroves, similar to the Indo-Pacific finless porpoise. Ideal substrates for this species are reefs and sandy bottoms, with temperatures between 15 
${ }^{\circ} \mathrm{C}$ and $36{ }^{\circ} \mathrm{C}$. Typical water depth for this cetacean is less than $20 \mathrm{~m}$ however they have been spotted up to $40 \mathrm{~m}$ in depth (Table 1).

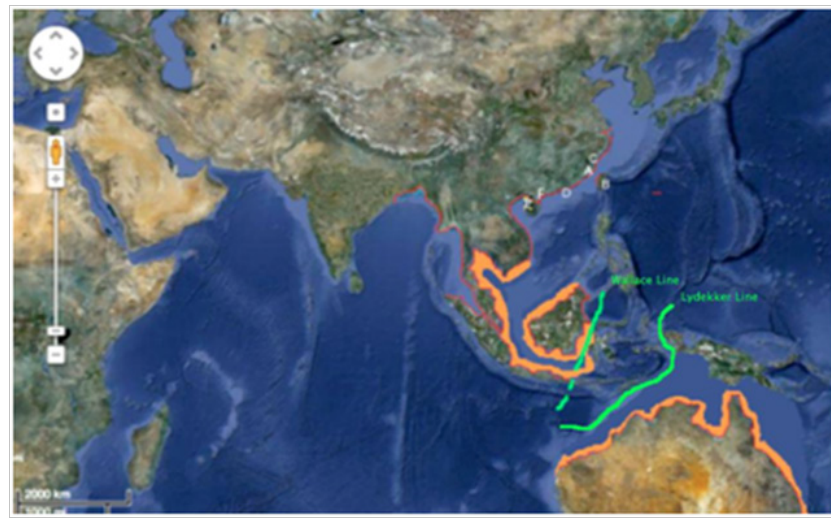

Figure 4 Hypothesized and confirmed distribution of Indo-Pacific Humpback Dolphin (Sousa chinensis).

\section{Indo-pacific bottlenose dolphin (Tursiops aduncus)}

Distribution: The results reveal that this species has the widest range of distribution between the five cetaceans. The Indo-Pacific bottlenose spatial attributions can be found from southern Africa, the northern rim of the Indian Ocean, throughout southern Asia, and extending to the lower half of Japan, and Jeju Islands in South Korea. This species is also found is various waters surrounding Australia, as well as portions of Papua New Guinea in the Solomon Islands (Figure 5). The Wallace and Lydekker line do not seem to be a factor for this species. They are distributed along both of the borders and do not seem to be restricted by the geographical barrier line (Figure 5).

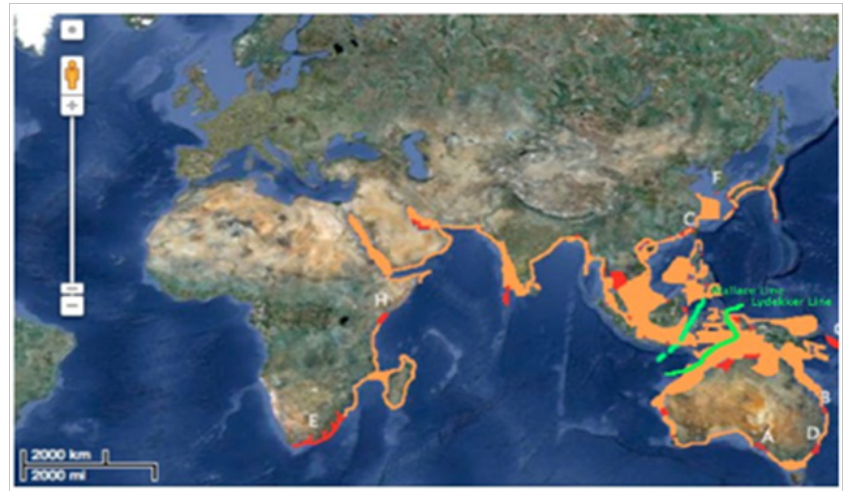

Figure 5 Hypothesized and confirmed distribution of Indo Pacific Bottlenose Dolphin (Tursiops aduncus).

Hypothesized regions of distribution (orange), primary region of distribution (red), Wallace line (green). Port River estuary, South Austraia (A). ${ }^{32}$ Queensland, Australia (B). ${ }^{33}$ Taiwan (C). ${ }^{34}$ Jervis Bay, Australia (D). ${ }^{35}$ Cape Vidal, Africa (E). ${ }^{36}$ Jeju Island, Korea (F) ${ }^{37}$ Solomon Islands (G). ${ }^{38}$ Zanzibar, Tanzania (H) ${ }^{39}$

Habitat: The Indo-Pacific bottlenose dolphin is a tropical species. They prefer reefs, and rocky bottom substrates in waters between 20 ${ }^{\circ} \mathrm{C}$ to $30{ }^{\circ} \mathrm{C}$ degrees. Compared to the other cetaceans, this species prefers the deepest coastal waters at approximately $100 \mathrm{~m}$. If needed, the Indo-Pacific bottlenose dolphin can survive in much deeper waters, as they have been spotted in depths up to $300 \mathrm{~m}$ (Table 1).

\section{Two species overlap}

Indo-pacific humpback and the Australian snubfin overlap within the northern portions of Australia. Above the Lydekker and Wallace line, the Indo-Pacific humpback and the Indo-Pacific finless porpoise overlap in the Malaysia and China area (Table 2).

\section{Three species overlap}

The Irrawaddy dolphin, the Indo-Pacific humpback and the IndoPacific finless porpoise all overlap within the Malaysia, regions of China and Bay of Bengal. In Australia, the Australian snubfin, IndoPacific bottlenose, and the Indo-Pacific humpback overlap. This shared habitat exists in the Beagle and Van Dieman Gulf as well as Brisbane, Australia (Table 2).

\section{Four species overlap}

Four species overlap within the inlets of Thailand and Cambodia as well as regions of Malaysia and Indonesia. The shared habitat exits between the Indo-Pacific bottlenose, the Indo-Pacific humpback, the Indo-Pacific finless porpoise and the Irrawaddy dolphin (Table 2).

\section{Discussion}

The first two objectives of gathering species habitat information, distribution and recording findings on a visual display were completed. The final objective was to predict reasoning behind certain distribution and overlap between the five cetaceans. When it comes to the overlapping display, some cetaceans seem to co-exist with others in specific areas. This may be due to the resources offered in a given area, which attract a diversity of species. ${ }^{2}$ A similar habitat requirement definitely seems to be a significant source in species overlap (Table 1).

The Indo-Pacific humpback dolphin and the Australian snubfin both share very similar habitat preferences. According to their distributional regions, it is clear that they overlap completely in northern Australia (Figure 6). Both species prefer estuarine waters and very shallow depths at approximately $30 \mathrm{~m}$ (Table 1).

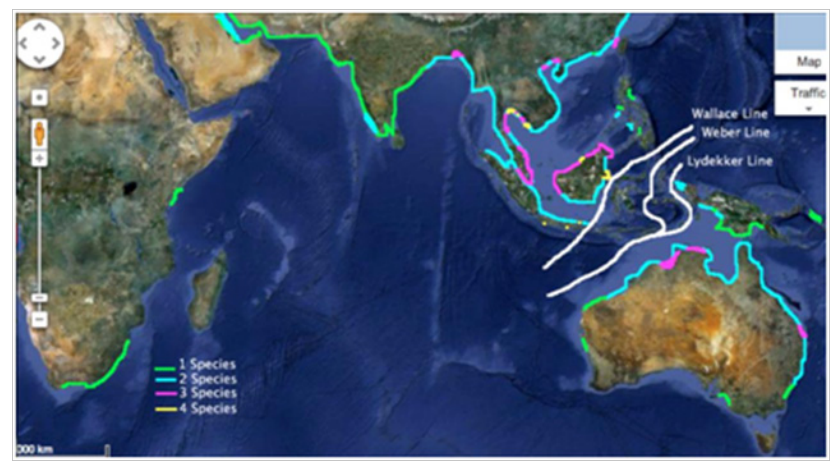

Figure 6 The overlapping distributions between the five cetaceans. One species (green), two species (blue), three species (pink), four species (yellow).

The Indo-Pacific humpback dolphin and Indo-Pacific finless porpoise overlap in the Malaysia and China area (Figure 6). These two species are very similar in their habitat preferences, where they both reside in estuary and mangrove regions. Each species resides in sandy and soft substrates. Neither cetacean is likely to travel in waters deeper than $30 \mathrm{~m}$ (Table 1 ).

The Irrawaddy dolphin, Indo-Pacific humpback dolphin and IndoPacific finless porpoise overlap in the Malaysia, China and Bay of Bengal area (Figure 6). All three species hare similar habitats where each prefers estuaries, muddy and sandy bottoms, and a water depth of approximately $40 \mathrm{~m}$ deep (Table 1 ). Overlap in these specific regions 
may have something to do with the shallow depths that surround the Malaysian region. Even though Indonesian waters connect to the same island, its deeper depths do not provide suitable living conditions for these three cetaceans. Considering the Irrawaddy dolphin is usually found in waters less than $18 \mathrm{~m}$ deep.$^{6}$ this species especially will not be found traveling around to the deeper Indonesian waters. The Bay of Bengal has many rivers exiting into the ocean, providing a wonderful source of estuarine waters, a suitable living environment for all three species .

The Australian snubfin, Indo-Pacific humpback, and Indo-Pacific bottlenose overlap in portions of northern Australia (Figure 6). All three species share common sandy bottom substrate similarities. The overlap that exists within the Beagle and Van Dieman Gulf may be due to the warm waters that enter the gulf, meeting the preferred habitat for the three cetaceans. The Indo-Pacific humpback and bottlenose dolphin are found in warmer waters around $20{ }^{\circ} \mathrm{C}-30{ }^{\circ} \mathrm{C}$ degrees (Table 1).

The Indo-Pacific humpback dolphin, Irrawaddy dolphin, IndoPacific finless porpoise, and Indo-Pacific bottlenose dolphin overlap in small regions of Malaysia, Indonesia, Thailand and Cambodia (Figure 6). Overlap might exist due to shared habitat similarities, where each cetacean prefers sandy and soft substrates (Table 1). The inlet of Thailand and Cambodia might offer more sheltered living conditions and food, resulting in the overlap between all four species. Borneo Mayalsia is another with high cetacean overlap. The Borneo rainforest covers many regions within Malaysia, existing very close to the coast where the four species overlap. The rainforest may provide an abundance of nutrient and fresh water to the surrounding ocean water, attracting many cetacean species ${ }^{8}$

The Sunda and Sahul shelf are regions of sunken land that consist of shallow waters surrounding present land. ${ }^{9}$ Cetacean distribution seems to be highly concentrated around the Sunda and Sahul Shelf. The sunken lands still offer shallow, warm waters suitable to all of the cetaceans. The area in between the two shelves is Wallacea. It is a biogeographical location that contains a group of Indonesian islands that are separated by different water channels.$^{10}$ There are three main underwater trench lines that exist in Wallacea: the Wallace line, Webber line and the Lydekker line. ${ }^{5}$ Both the Wallace and Lydekker line seem to play a significant role in isolating some of the cetaceans to certain regions. The deep underwater trenches act as a barrier, preventing the species who cannot survive in high depth from crossing over. The Indo-Pacific finless porpoise seems to be greatly impacted by the Wallace line (Figure 3). The species remains above the Wallace line because the deep trenches act as a barrier, preventing them from crossing.

The Irrawaddy dolphin also remains to be distributed above the Wallace line however there have been one confirmed sighting in Indonesia where the species was found bellow the Wallace line (Figure 2). The population below the line may have become isolated to this area of water throughout the earth's transitions over millions of years. The Indonesian islands were once attached and part of an area of land called Indochina. ${ }^{11}$ This area was positions up where China is now located. As the tectonic plates moved, that marine animals moved as well. At some point in history, it is possible that a population of the Irrawaddy dolphin became separated and found suitable habitat on one of the Indonesian islands. Since this species can only travel in waters up to $18 \mathrm{~m}$ in depth, it restricts them to remain where shallow waters exist. ${ }^{6}$ The fact that the Irrawaddy population might have become isolated bellow the Wallace millions of years ago, suggests that it might have evolved into a separate species from the population above the Wallace line. ${ }^{12}$ It is also possible that the sighting was recorded incorrectly and it was not in fact an Irrawaddy dolphin.

Three sightings of Irrawaddy dolphins have been recorded in the Philippines. The waters that surround this island travel much deeper than $18 \mathrm{~m}$ in depth (Figure 7). It is likely that the Philippines populations are isolated to this island as the deep surrounding waters act as a barrier for the cetacean. The Australian snubfin is a cetacean that is significantly affected by the Lydekker line (Figure 1). The biogeographical line acts as a barrier to the species, preventing the population from crossing the deep under water trenches. The southern population of the Indo-Pacific humpback dolphin is isolated to the same area of land as the Australian snubfin, where the Lydekker line acts as a significant biogeographical barrier (Figure 4). The northern population of this cetacean however is isolated to the same area of land as the Irrawaddy dolphin, where the Wallace line acts as a significant biogeographical barrier (Figure 4).

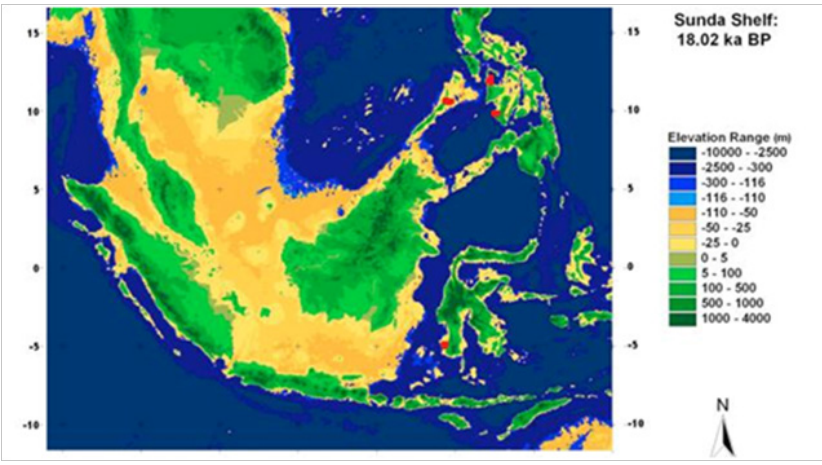

Figure 7 Chart revealing water depth $(m)$ in the Sunda Shelf region.

The Australian snubfin and Irrawaddy dolphin were once thought to be the same species, regardless of the gap in their distribution within the Wallacean region. Upon further investigation, it was discovered that the two populations had diverged into two separate species because of the biogeographical isolation barrier. ${ }^{12}$ It is possible that the same divergence occurred between the north and south population of the Indo-Pacific humpback dolphin. The isolation between the populations over millions of years might have lead to a divergence in two separate species.

The Indo-Pacific humpback dolphin and the Australian snubfin dolphin overlap in distribution across northern Australia due to a similar habitat preference (Table $1 \& 2$ ). It is peculiar however how the Indo-Pacific humpback does not overlap with the Australian snubfin in Papua New Guinea considering the suitable habitat conditions. The Indo-Pacific humpback dolphin remains isolated to the northern Australian region only. This occurrence may have be the cause of tectonic plate movement. Papua New Guinea was once attached to Australia in an ancient sub continental plate known as Gondwana. ${ }^{13}$ When the plates began to separate the two areas of land 65 to130 million years ago, both cetaceans may have moved as well. Since the habitat preferences between the Indo-Pacific humpback and Australian snubfin are slightly different, it is possible that the Papua New Guinea surroundings were more suitable to the Australian snubfin resulting in extirpation of the humpback dolphin. The Indo-Pacific bottlenose dolphin does not seem to be affected by either of the biogeographical lines (Figure 5). This cetacean has the ability to travel in waters up to $300 \mathrm{~m}$ in depth, therefore this characteristic might prevent the Wallace and Lydekker line from acting as a barrier. Osteology and morphology plays a large role in determining the type of habitat a cetacean can survive in. ${ }^{14}$ Certain cranial structure may be designed for deep-water 
exploration such as the Indo-Pacific bottlenose dolphin. Cetaceans have a specific amount of body fat that they use to thermo regulate their bodies in different water temperatures. Cetaceans that belong to warmer bodies of water, such as the Indo-Pacific humpback dolphin is likely to have separate body fat to a cetacean that resides in cold water. It is possible that the Indo-Pacific humpback dolphin does not reside within Papua New Guinea due to osteology restrictions. The Australian snubfin may possess certain osteology characteristics, making it more suitable to the Papua New Guinea environment.

There are over 17,000 Indonesian islands, many of them which most likely are inhabited by cetacean species. ${ }^{15}$ According to up to date journal article records, there are no recorded sightings of the five cetacean species other than one Irrawaddy sightings and a couple Indo-Pacific bottlenose within the Indonesian islands. It is difficult to conduct research and surveys for cetacean spotting are throughout the thousands of Indonesia. It is possible that many more of the five cetaceans studied inhabit the islands in Wallacea, and have simply become isolated to the islands due to the deep underwater trenches that surround the area. It is possible that new species have developed due to divergence and isolation to some Indonesian Islands. A future area of study would be to investigate some of the Indonesian islands that meet suitable habitat requirements for the presence of IndoPacific cetaceans. This could help expand the accuracy of many cetaceans distributions

Another are for future study would be to gather blood samples of the two populations of the Indo-Pacific humpback dolphin, to determine if the northern population has diverged into a separate species from the southern population. It would also be interesting to investigate why the Indo-Pacific humpback dolphin does not reside in the Papua New Guinea region with the similar habitat preference cetacean, the Australian snubfin. The Indo-Pacific bottlenose dolphin has a very large distributional region that consists from Africa to Australia; it is possible that different species have diverged along the spread of its spatial location. The Indo-Pacific Humpback dolphin was once thought to be the same species throughout its large distribution from Africa to Australia however, with further investigation of the skull morphology, three separate species were identified throughout the original spatial location. ${ }^{14}$

One of the main factors that seemed to play a role in individual cetacean distribution was the impact of geographical barriers. The Wallace and Lydekker line seem to be the most influential in isolating populations from one another. The barriers that exist within Wallacea have separated cetacean populations from one another to the point where new species have diverged such as the Australian snubfin and Irrawaddy dolphin. It is likely that the same barrier caused the northern and southern Indo-Pacific humpback dolphin populations to diverge into separate species. Water depth and habitat preference seem to also play a significant role when it comes to species overlapping distributions. There was a correlation between shared habitat interests with cetacean overlap. Unfortunately, many records of cetacean distribution are based from hypothetical a conclusion, which makes accurate spatial location difficult to obtain. Therefore there may be further overlap that exists between the five cetacean species.

\section{Acknowledgments}

None.

\section{Conflicts of interest}

None.

\section{References}

1. Abu Talib, Mohammad Isa, I Mohamad Saupi, Y Sharum Status of demersal fishery resources of Malaysia. pp. 2003;83-136.

2. Biusing ER Assessment of Coastal Fisheries in the Malaysian-Sabah portion of the Sulu-Sulawesi Marine Ecoregion (SSME) WWF Malaysia. Buhavan Infotech, Sabah, Malaysia. 2001

3. Galid RS Investment Prospects and Potential in the Fisheries Sector in Sabah. Department of Fisheries, Sabah. 2001

4. Teh L, Cabanban AS, Sumaila UR The reef fisheries of Pulau Banggi, Sabah: A preliminary profile and assessment of ecological and socioeconomic sustainability. Fisheries Research. 2005;76(3):359-367.

5. Vidthayanon C Species composition and Diversity of Fishes in the South China Sea, Area I: Gulf of Thailand and East Coast of Peninsular Malaysia. SEAFDEC. 1998

6. Chia CB Ko-Nelayan's role and experience in increasing living standards. Workshop on Strategies to Reduce the Poverty Rate amongst Fishing Communities. Institute for Development Studies (IDS), Sabah, Malaysia. 1992

7. Sabah Tourism Sabah Tourism Report 2000/2001. Sabah Tourism Promotion Corporation, Malaysia. 2002

8. Ambak MA Sabah: The Fisheries Status. UPM Press Publication, Serdang, Malaysia. 2002

9. Chin PK Marine food fishes and fisheries of Sabah. Natural History Publications, Kota Kinabalu, Malaysia.1998.

10. Chua TE, Mathias JA Coastal resources of West Sabah. An investigation into the impact of oil spill. Penerbit Universiti Sains Malaysia, pp. $1978 ; 296$.

11. Mohsin AKM, Ambak MA Marine fishes and fisheries of Malaysia and neighboring countries. Universiti Pertanian Malaysia Press, Serdang, Malaysia, pp. 1978;743.

12. Department of Statistics (DOS) 2010 Population and Housing Census of Malaysia. Annual Bulletin of Statistics 2011. Department of Statistics, Sabah, Malaysia. 2011

13. Integrated Coastal Zone Management Unit (ICZM) abah Coastal Zone Profile. Danish Cooperation for Environment and Development (DANCED). Town and Regional Planning Department, Kota Kinabalu, Sabah, Malaysia. 1998

14. Biusing ER Status of the coastal fisheries resources of Sabah. Paper presented at the Seminar on Sustainable. Development of Fishery Resources, Kota Kinabalu, Malaysia. 1995

15. Galid RS Prospects and Potential in the Fisheries Sector in Sabah. Paper presented at the Seminar Pembangunan Ekonomi Setempat Dalam Era Globalisasi. Institue Development Studies, Sabah. 1998

16. Biusing ER, Gambang AC, Jumin R, M Manjaji Demersal fisheries resources along the west coast of Sabah. Department of Fisheries, Sabah, Malaysia. 1994

17. Biusing ER, R Rumpet Results of demersal fishery resources survey along the Sarawak/Sabah waters during the 1996-1997 period. Draft technical report submitted to SEAFDEC. 1995

18. Garces LR, Alias M, Abu Talib A, et al, A trophic model of the coastal fisheries ecosystem off the West Coast of Sabah and Sarawak, Malaysia, pp. 2003;333-352.

19. Awong H, Ibrahim S, Somo K, et al. Stock Assessment by Swept Area Method in the Darvel Bay, Sabah, Malaysia. World Journal of Fish and Marine Sciences. 2011;3(5):361-365.

20. Rumpet R, Awang J, Musel E, et al. Distribution, Abundance and Biological Studies of Economically Important Fishes in the South China Sea, Area II: Sarawak, Sabah and Brunei Darussalam Waters. Fisheries Research Center, Department of Fisheries, Sabah, Malaysia. 2011 
21. Jakobsen FN, Hartstein J, Frachisse T, et al. Sabah shoreline management plan (Borneo, Malaysia): Ecosystems and pollution. Ocean \& Coastal Management. 2007;50(1-2):84-102.

22. Hilborn R, Walters CJ Quantitative Fisheries Stock Assessment. Choice, Dynamics and Uncertainty.Chapman and Hall, New York, USA, pp. $1992 ; 570$.

23. Seijo JC, O Defeo, S Salas Fisheries bioeconomics: Theory, modeling and management. FAO Fisheries Technical Paper No. 368. FAO, Quebec City, Canada, pp. 1998;08.

24. Walters CJ, Martell SJD Fisheries Ecology and Management. Princeton University Press, Princeton, USA, pp. 2004;399.

25. Hoggarth DD, Abeyasekera S, Arthur RI, et al. Stock assessment for fishery management - A framework guide to the stock assessment tools of the Fisheries Management Science Programme (FMSP). FAO Fisheries Technical Paper No. 487, FAO, Rome, Italy, pp. 2006;261.

26. FAO Fisheries Management. FAO Technical Guidelines for Responsible Fisheries. No. 4. FAO, Rome, Italy, p. 1997;68.

27. FAO Guidelines for the routine collection of capture fishery data. FAO Fisheries Technical Paper No. 382. FAO, Rome, pp. 1999;113.

28. Pauly DG, Gaschutz Simple method for fitting oscillating length growth data with a program for pocket calculator. ICES, Denmark, p. 1979;26.

29. Pauly DN, David ELEFAN I, a basic program for the objective extraction of growth parameters from length-frequency data. Meeresforcch. 1981;28(4):205-211.

30. Pauly D Fish population dynamics in tropical waters. A manual for use with programmable calculators. ICLARM Contribution No. 143, Manila, Philippines. 1984

31. Polovina JJ Model of a coral reef system I: the ECOPATH model and its application to French Frigate Scholars. Coral Reefs. 1984; 3:1-11.
32. Polacheck TR, Hilborn AE, Punt Fitting surplus production models: comparing methods and measuring uncertainty. Canadian Journal of Fisheries and Aquatic Sciences. 1993;50(12):2597-2607.

33. Maunder MN, Punt AE Standardizing catch and effort data: a review of recent approaches. Fish Res . 2004;70:141-159.

34. Department of Fisheries (DOF) Marine Fisheries Statistics - State of Sabah. Department of Fisheries, Sabah, Malaysia. 2013

35. FAO Fisheries Management. FAO Technical Guidelines for Responsible Fisheries. No. 4. FAO, Rome, Italy, p. 1995; 68.

36. FAO Guidelines for the routine collection of capture fishery data. FAO Fisheries Technical Paper No. 382. FAO, Rome, Italy, pp. 1996;113.

37. Teh L SL, Zeller D, Cabanban S et al. Seasonality and historic trends in the reef fisheries of Pulau Banggi, Sabah, Malaysia. Coral Reefs. 2007; 26:251-263.

38. Awong HS, Ibrahim K, Somo MA, et al. Observation on Weight Length Relationship of Priacanthus tayenus (Richardson, 1846) Species in Darvel Bay, Sabah, Malaysia. World Journal of Fish and Marine Sciences. 2011;3(3):239-242.

39. Rayner SG Investment Prospects and Potential in the Fisheries Sector in Sabah Fisheries Department of Sabah, Malaysia. 2011

40. Anonymus Two more projects to release aquatic life into rivers. Borneo Post, p. 2012; A2.

41. Morpi M Shrinking marine resources threaten fishery, tourism. Borneo Post, p. 2012;4.

42. Mu P Overfishing contributes to diminishing fishery resources. Borneo Post, p. 2012;12.

43. Toha $\mathrm{T}$ The Influence of Seasonal Changes on Physico-Chemical Characteristics of Seawater in Sepangar and Gaya Bays, Sabah. Master Thesis, Borneo Marine Research Institute, Universiti Malaysia Sabah. 2008. 